University of Wollongong

Research Online

Faculty of Engineering and Information

Faculty of Engineering and Information

Sciences - Papers: Part A

Sciences

$1-1-2017$

\title{
Effects of fabrication technique on tensile properties of fiber reinforced polymer
}

Thong m. Pham

Curtin University, University of Wollongong, thong.pham@curtin.edu.au

Muhammad N. S Hadi

University of Wollongong, mhadi@uow.edu.au

Jim Youssef

University of Wollongong, jy201@uowmail.edu.au

Follow this and additional works at: https://ro.uow.edu.au/eispapers

Part of the Engineering Commons, and the Science and Technology Studies Commons

Research Online is the open access institutional repository for the University of Wollongong. For further information contact the UOW Library: research-pubs@uow.edu.au 


\title{
Effects of fabrication technique on tensile properties of fiber reinforced polymer
}

\author{
Abstract \\ This study investigated the effects of fabrication technique on the tensile properties of fiber reinforced \\ polymer (FRP) flat coupon tests. A total of 20 FRP flat coupons were prepared by two different \\ techniques, which were tested in tension until failure. The first technique of preparing the FRP coupons \\ was based on the recommendation of ASTM D7565/D7565M-10, named the "Cutting Technique," while \\ the second technique, named the "Folding Technique," was proposed by this study. Experimental results \\ from this study indicated that preparing FRP coupons using the Cutting Technique resulted in a reduction \\ in the tensile properties as compared to coupons prepared by the proposed Folding Technique. Most \\ notably, the tensile force per unit width obtained by the FRP flat coupons prepared using the Folding \\ Technique was up to $8 \%$ higher than that obtained by coupons prepared using the Cutting Technique. In \\ addition, the effect of the \% bending on the tensile properties was also studied. It was found that the \% \\ bending about the thickness plane was greater than that of the \% bending about the width plane. \\ Furthermore, the tensile properties of the FRP coupons were not sensitive to its \% bending.

\section{Disciplines} \\ Engineering | Science and Technology Studies \\ Publication Details \\ Pham, T. M., Hadi, M. N. S. \& Youssef, J. (2017). Effects of fabrication technique on tensile properties of \\ fiber reinforced polymer. Journal of Testing and Evaluation, 45 (5), 1524-1534.
}




\section{Journal of \\ Testing and Evaluation}

T. M. Pham, ${ }^{1}$ M. N. S. Hadi, ${ }^{2}$ and J. Youssef ${ }^{2}$

DOI: 10.1520/JTE20150525

Effects of Fabrication Technique on Tensile Properties of Fiber Reinforced Polymer 
doi:10.1520/JTE20150525 / Vol.45 / No.5 / September 2017 / available online at www.astm.org

Manuscript received December 29, 2015: accepted for publication July 11, 2016; published online September 9, 2016.

${ }^{1}$ Center for Infrastructural Monitoring and Protection, School of Civil and Mechanical Engineering, Curtin Univ., Kent St., Bentley, WA 6102, Australia (Corresponding author), e-mail: thong.pham@curtin.edu.au

${ }^{2}$ School of Civil, Mining and Environmental Engineering, Univ. of Wollongong, Northfields Ave, Wollongong, NSW 2522, Australia
T. M. Pham, ${ }^{1}$ M. N. S. Hadi, ${ }^{2}$ and J. Youssef ${ }^{2}$

\section{Effects of Fabrication Technique on Tensile Properties of Fiber Reinforced Polymer}

\section{Reference}

Pham, T. M., Hadi, M. N. S., and Youssef, J., "Effects of Fabrication Technique on Tensile Properties of Fiber Reinforced Polymer," Journal of Testing and Evaluation, Vol. 45, No. 5, 2017, pp. 1524-1534, http:// dx.doi.org/10.1520/JTE20150525. ISSN 0090-3973

\section{ABSTRACT}

This study investigated the effects of fabrication technique on the tensile properties of fiber reinforced polymer (FRP) flat coupon tests. A total of 20 FRP flat coupons were prepared by two different techniques, which were tested in tension until failure. The first technique of preparing the FRP coupons was based on the recommendation of ASTM D7565/D7565M-10, named the "Cutting Technique," while the second technique, named the "Folding Technique," was proposed by this study. Experimental results from this study indicated that preparing FRP coupons using the Cutting Technique resulted in a reduction in the tensile properties as compared to coupons prepared by the proposed Folding Technique. Most notably, the tensile force per unit width obtained by the FRP flat coupons prepared using the Folding Technique was up to $8 \%$ higher than that obtained by coupons prepared using the Cutting Technique. In addition, the effect of the \% bending on the tensile properties was also studied. It was found that the \% bending about the thickness plane was greater than that of the \% bending about the width plane. Furthermore, the tensile properties of the FRP coupons were not sensitive to its \% bending.

\section{Keywords}

fiber reinforced polymer, tensile strength, failure investigations, material tests, coupon tests, wet lay-up materials

\section{Introduction}

Confinement of reinforced concrete columns with externally bonded fiber reinforced polymer (FRP) laminates is an effective rehabilitation technique to enhance the columns' capacity [1-3]. Failure of an FRP confined concrete column is usually governed by the rupture of the FRP, and designers consequently need to know the strain and stress at which the rupture of the FRP will 
occur [4]. It has been observed that there is a considerable variation in the experimental rupture strain of FRP. The rupture of FRP is about $58 \%-91 \%$ of its ultimate tensile strength determined from flat coupon tests [5]. It is noted that the actual rupture strain of FRP is necessary to estimate the axial strength of FRP confined concrete [6-8]. The actual rupture strain of the jackets in FRP confined concrete columns can be estimated from the ultimate tensile strength determined from flat coupon tests. The strain efficiency factor can be utilized in such cases, which can be found in the study by Lam and Teng [8]. It has also been reported that carbon fiber materials exhibit higher modulus of elasticity and tensile strength, but lower rupture strain as compared to those of glass fibers. Furthermore, when carbon and glass fibrous materials are bonded together to achieve a hybrid composite laminate, the glass fibers delay the progress of fracture of the carbon fibers providing an increase in the elongation of the hybrid laminate [9]. There have been a limited number of studies about the mechanical properties of FRP [10-12]. Therefore, determining the ultimate tensile strength from flat coupon tests is significantly important. It is obvious that the implementation of FRP coupons and the workmanship affect the ultimate strength of the FRP coupons [13]. There are two common types of FRP composites: shopmanufactured FRP composite and wet lay-up FRP composite. This study focuses on the wet lay-up FRP composite materials.

There have been two standards which can be utilized to conduct FRP coupon tests; these are ASTM D3039/D3039M14[14] and ASTM D7565 [15]. The standard ASTM D3039 [14] provided helpful knowledge to determine the tensile strength of FRP coupons. However, this standard does not mention details about the preparation of the FRP coupons. Subsequently, the standard ASTM D7565 [15] was revised and details of the fabrication technique were addressed. However, some requirements in the standard ASTM D7565 [15], in terms of the preparation of the coupons, result in some difficulties when conducting FRP flat coupon tests. ASTM D7565 [15] recommends producing a laminated FRP with a minimum dimension of 300 by $300 \mathrm{~mm}$, from which flat coupons are cut at the required dimensions for testing. However, the cutting fabrication technique may damage some fibers in the coupons; this in turn may lead to a reduction of the ultimate tensile strength of the FRP coupons and a degradation in the quality control. Therefore, this study introduces a new technique for the preparation FRP flat coupons for the purpose of tensile testing, which provides an alternative fabrication technique with reliable and consistent results.

\section{Tensile Properties of FRP Sheets}

\section{REVIEW OF TEST STANDARDS}

The contemporary standard test method for determining the tensile properties of fiber reinforced polymer matrix composites for the use in structures requiring strengthening is
ASTM D7565 [15]. The other constituents of externally bonded strengthening systems, such as the adhesives, primer, and putty used to bond the FRP material to the substrate are excluded from the sample preparation and testing methods. This standard directly references and relies on the previous standard ASTM D3039 [14] for specimen selection and the procedure of testing. The main difference between the two standards, however, is the determination of the tensile properties of the FRP composite material and most notably the ultimate tensile strength. ASTM D3039 [14] states that the ultimate tensile strength of the FRP composite is calculated as the maximum tensile load carried before failure divided by the average cross sectional area of the specimen. This gives rise to an ultimate tensile strength in terms of ultimate tensile stress in units of MPa. On the other hand, ASTM D7565 [15] expresses the ultimate tensile strength in force per unit width $(\mathrm{N} / \mathrm{mm})$ as calculated by the maximum tensile load before failure divided by the width of the specimen. In addition, for the determination of the tensile chord modulus of elasticity, ASTM D7565 [15] refers to the procedure in ASTM D3039 [14], but substitutes the specimen width for the specimen area. Therefore, as opposed to ASTM D3039 [14], the specimen thickness is not required for the calculation of the tensile properties in ASTM D7565 [15]. Therefore, ASTM D7565 [15] eliminates the "design thickness," which is a parameter difficult to determine accurately by the tests, but defined by each supplier of FRP system.

The standard ASTM D3039 [14] does not mention information about the fabrication technique for preparing FRP coupons. This standard requires testing at least five specimens per test condition unless valid results can be gained by using fewer specimens. As a result, using the wet lay-up FRP method for the specimen fabrication is currently inconsistent among researchers worldwide. The standard ASTM D7565 [15] addressed this deficiency in the previous standard [14] then filled in this gap, which is described in Section 8.3.1. Based on this standard, a polymer release film, typically 600 by $600 \mathrm{~mm}$ is placed on a smooth, flat horizontal surface. Resin is first applied to the release film. The first ply of dried fiber with a minimum dimension of 300 by $300 \mathrm{~mm}$ is saturated or coated with the specified amount of resin and placed on the release film. The specified number of plies are sequentially impregnated with resin and stacked onto the release film using the specified amount of resin. A second release film is then placed over the material to provide protection. In order to ensure a smooth top surface of the FRP material, a rigid flat plate should be placed on top of the top layer of release film while the resin cures. After the specified curing procedure is complete, the release films are removed from the panel. Specimens may be cut and tabbed after the curing procedure. It is worth confirming that this fabrication technique is referred to as the "Cutting Technique" in this study. 
In addition, it is obvious that this wet lay-up method is essentially based and governed by the workmanship in preparing the coupons. It is very difficult to ensure the perfect alignment of fibers or bundles of fibers. This means that if the specimen is cut at a straight line, some fibers will definitely be transected and damaged. These cuts lead to an uncertainty in the number of fibers in a specimen, resulting in some specimens having a different number of fibers from other specimens. As a result, the tensile strength of these specimens may not be expected to be the same. Therefore, this study introduces a Folding Technique for specimen fabrication and compares the tensile strength of the FRP coupons obtained by the Cutting Technique and the Folding Technique. The Folding Technique is described in more details in the sections below.

\section{TENSILE PROPERTIES}

In presenting the results, the ultimate tensile strength expressed as force per unit width and the tensile chord modulus of elasticity are calculated based on the following equations from ASTM D7565 [15]. The thickness and width of each specimen are determined by taking the average of three measurements at different sections of the specimen, which included a reading at each end of the specimen close to the steel tabs and one reading at mid length.

$$
F^{*}=\frac{P^{\max }}{w}
$$

where:

$F^{*}=$ maximum tensile force per unit width,

$P^{\max }=$ maximum tensile force before failure, and

$w=$ width of the specimen.

$$
K^{*}=\frac{\frac{\Delta P}{w}}{\Delta \varepsilon}
$$

where:

$K^{*}=$ the chord tensile stiffness per unit width,

$\Delta P=$ difference in applied tensile force between the two strain points, 1000 and $3000 \mu \varepsilon$ as explained in Table 3 of ASTM D3039 [14], and

$\Delta \varepsilon=$ difference between the two strain points, nominally 0.002 (Table 3, ASTM D3039 [14]).

\section{BENDING EFFECTS}

In the standard ASTM D3039 [14], the bending effects on the tensile strength of FRP coupons are mentioned and analyzed. The standard mentions that excessive bending will result in premature failure and inaccuracies in determining the modulus of elasticity. The bending may be due to poor system alignment (misaligned grips) or poor specimen preparation or specimens installed improperly in the grips. The \% bending can be evaluated using Eqs 3, 4, and 5 as follows:

$$
\begin{gathered}
B_{y}=\frac{\varepsilon_{\text {ave }}-\varepsilon_{3}}{\varepsilon_{\text {ave }}} \times 100 \\
B_{z}=\frac{\frac{2}{3}\left(\varepsilon_{2}-\varepsilon_{1}\right)}{\varepsilon_{\text {ave }}} \\
\varepsilon_{\text {ave }}=\frac{\frac{\left(\varepsilon_{1}+\varepsilon_{2}\right)}{2}+\varepsilon_{3}}{2}
\end{gathered}
$$

where:

$B_{y}=\%$ bending about system $y$ axis (about the narrow plane), detailed in ASTM D3039 [14],

$B_{z}=\%$ bending about system $z$ axis (about the wide plane), detailed in ASTM D3039 [14], and

$\varepsilon_{1}, \varepsilon_{2}$, and $\varepsilon_{3}=$ indicated longitudinal strains displayed by Gages 1, 2, and 3, respectively, of Fig. 1.

It is recommended by ASTM D3039 [14] that good testing practice is generally able to limit \% bending to a range from 3 to $5 \%$ at moderate strain levels $(>1000 \mu \varepsilon)$. A system showing excessive bending for the given application should be adjusted or modified.

\section{Experimental Program}

\section{DESIGN OF EXPERIMENTS}

A total of 20 standard FRP coupons were made and tested at the High Bay Laboratory of the University of Wollongong. In this study, two different techniques of preparing coupons for tensile testing were implemented and analyzed, which included the Cutting Technique outlined in the ASTM D7565 [15] test standard and a proposed Folding Technique that did not involve exposing the reinforcing fibers. These 20 coupons were divided into four groups in which each group consisted of five specimens.

The notation of the coupons consists of two parts: the first part states the technique used to prepare the coupons, with " $\mathrm{C}$ " and "F" representing the Cutting Technique and Folding Technique, respectively. The coupon preparation utilizing these techniques is discussed in the sections below. The second part is either a number " 25 " and " 37.5 " stating the width of the coupons. It should be noted that the $25 \mathrm{~mm}$ width coupons, C25 and F25, were prepared using 3 layers of CFRP, whereas the $37.5 \mathrm{~mm}$ width coupons were composed of 2 layers of CFRP. Aluminum tabs with a thickness of $3 \mathrm{~mm}$ each were bonded to the ends of the coupons in order to transfer the force from the grip of the testing machine into the coupons. The dimensions of the coupons and aluminum tabs are shown in Fig. 1. Details of the coupons are presented in Table 1.

\section{SPECIMEN PREPARATION}

In this study, one type of CFRP was used to prepare the coupons for tensile testing. The CFRP had a unidirectional fiber 
FIG. 1

FRP flat coupons.

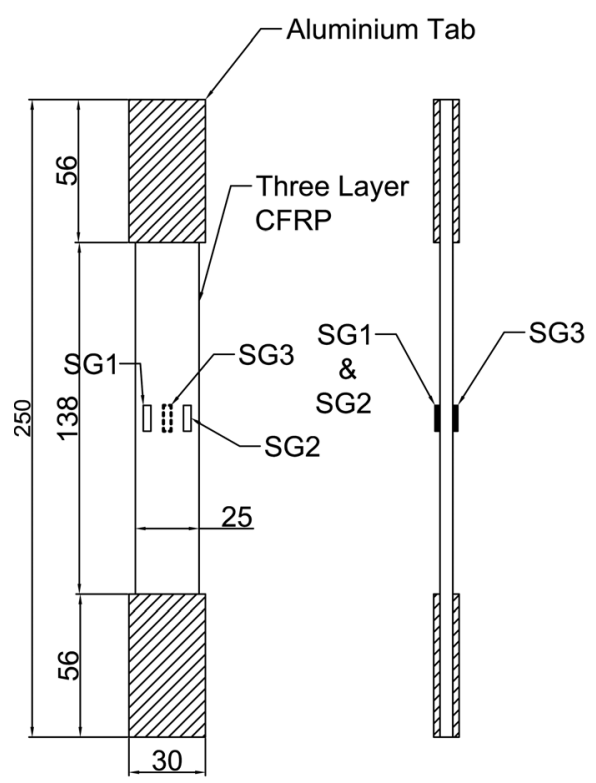

Front view
Side view

$25 \mathrm{~mm}$ coupons

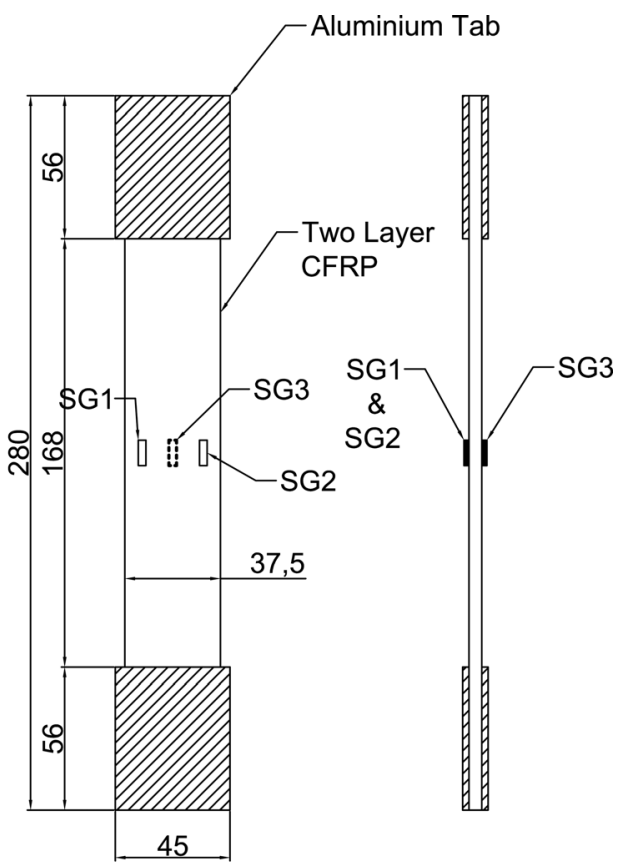

Front view

$37.5 \mathrm{~mm}$ coupons density of $340 \mathrm{~g} / \mathrm{m}^{2}$, a nominal width of $75 \mathrm{~mm}$, and a nominal thickness of $0.45 \mathrm{~mm}$ per sheet of fiber. The CFRP coupons were prepared following the ASTM D7565 [15] wet lay-up process, which involved the impregnation of the fiber sheets with the matching epoxy resin. The epoxy resin was prepared using a mixture of liquid epoxy resin and a hardener at a ratio of 5:1. The required number of sheets of dry fiber are consecutively saturated with resin and stacked to produce a flat rigid plate once the resin cures and hardens. In this standard, the dry fiber sheets are recommended to have a minimum dimension of 300 by $300 \mathrm{~mm}^{2}$ and the cured plate is cut into coupons or strips to meet the required dimensions. However, the carbon fiber dry sheets used in this experimental study and in other experimental studies [16-19] cannot be manufactured with minimum dimensions of 300 by $300 \mathrm{~mm}$ as recommended. It is worth mentioning that most of the studies focusing on FRP did not provide details about the specimen fabrication in terms of the preparation of the cured plate and the subsequent method of cutting it into smaller coupons. Furthermore, the cutting of the FRP plate into coupons penetrates the matrix material and in turn exposes and damages the reinforcing fibers, which may result in unexpected coupon failures or reduced strength.

With reference to ASTM D7565 [15], the minimum width for unidirectional wet lay-up FRP specimens that have bundles (i.e., roving or tows) not wider than $3 \mathrm{~mm}$ when laid into the laminate, should be $25 \mathrm{~mm}$. Taking this into account and considering the carbon fiber dry sheets had a nominal width of $75 \mathrm{~mm}$, four groups of coupons were created having widths of $25 \mathrm{~mm}$ and $37.5 \mathrm{~mm}$ as shown in Table 1. The folded coupons denoted by F25 and F37.5 were prepared by evenly folding a $75 \mathrm{~mm}$ width dry carbon fiber sheet saturated with epoxy. To produce the Group F37.5 specimens, the epoxy saturated carbon sheet was folded once along the vertical axis to produce a $37.5 \mathrm{~mm}$ width two layered specimens, as shown in Fig. 2a. Similarly, the Group F25 specimens were prepared by folding the $75 \mathrm{~mm}$ wide sheet twice along the vertical axis to produce 25

TABLE 1 Test matrix.

\begin{tabular}{|c|c|c|c|c|c|c|}
\hline Group & No. of Coupons & Width $(w, \mathrm{~mm})$ & Length $(l, \mathrm{~mm})$ & No. of FRP layers & Preparation Technique & Type of FRP \\
\hline $\mathrm{C} 25$ & 5 & 25 & 250 & 3 & Cutting & CFRP \\
\hline F25 & 5 & 25 & 250 & 3 & Folding & CFRP \\
\hline C37.5 & 5 & 37.5 & 280 & 2 & Cutting & CFRP \\
\hline F37.5 & 5 & 37.5 & 280 & 2 & Folding & CFRP \\
\hline
\end{tabular}


FIG. 2

Preparation of the specimens using the Folding Technique.

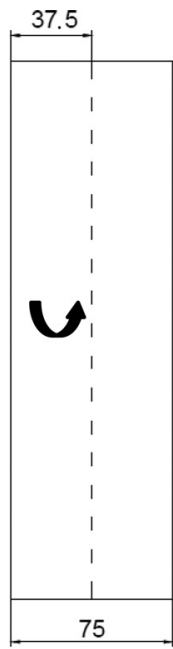

First Fold

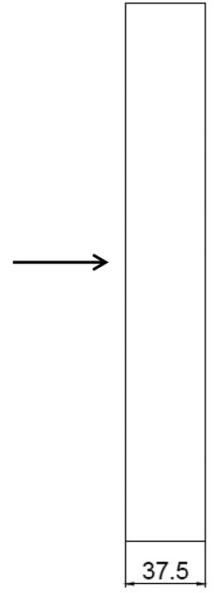

F37.5 Specimen (a) Group F37.5 Specimens

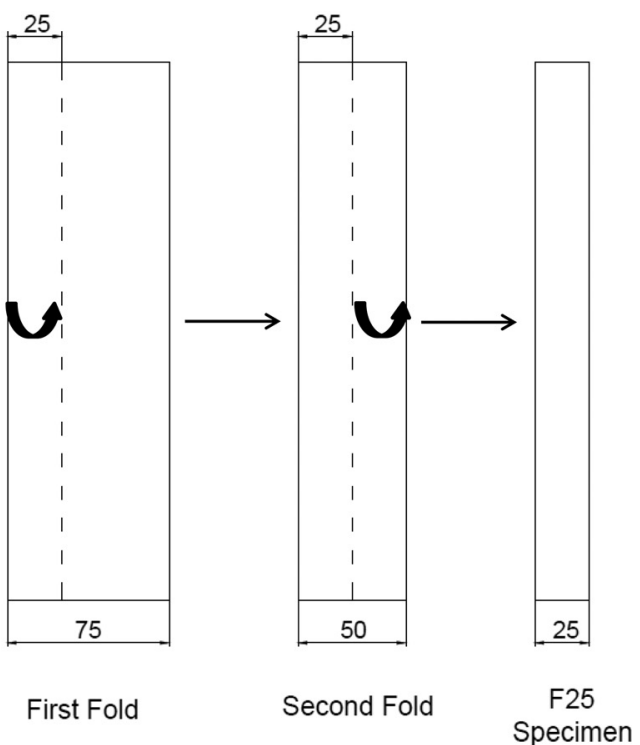

(b) Group F25 Specimens mm width three layered specimens, as shown in Fig. 2b. In order to compare the specimens prepared by the proposed Folding Technique to specimens prepared using the Cutting Technique following ASTM D7565 [15], equivalent specimens prepared by cutting a cured $75 \mathrm{~mm}$ wide FRP plate into widths of 25 and $37.5 \mathrm{~mm}$ were produced. These specimens are denoted by C25 and C37.5. As discussed above, these hardened FRP plates were produced by stacking saturated $75 \mathrm{~mm}$ width fiber sheets to produce 2 layered C37.5 specimens or 3 layered C25 specimens. The dimensions of the specimens are shown in Fig. 1.

\section{TESTING INSTRUMENTATION}

In order to measure the axial strains of the CFRP coupons, a total of three longitudinal strain gages were attached. These included one strain gage bonded to the back face of the specimen and another two at the front face at mid-length across the width of the specimen, as shown in Fig. 1. As mentioned in the ASTM D3039 [14], the amount of bending in the thickness plane $\left(B_{y}\right)$ and width plane $\left(B_{z}\right)$ can be measured by analyzing the variations in strain between these three strain gages as shown in Eqs 3, 4, and 5.

The tensile tests for all the coupons were conducted using a screw-driven material testing machine known as the Instron 8033. As mentioned above, aluminum tabs were bonded to the ends of the specimens in order to transfer the force from the grip of the machine into the specimen. The dimensions of these tabs are shown in Fig. 1. The load was applied at a constant head displacement rate of $1 \mathrm{~mm} / \mathrm{min}$ in order to ensure specimen failure occurs within 1 to $10 \mathrm{~min}$ as highlighted in ASTM
D3039 [14]. The load was measured using a load cell of $500 \mathrm{kN}$ capacity. The readings of the load and strain gages were taken using a data logging system and were subsequently saved in a control computer which recorded one recording per second. In presenting the results, the strains were averaged from the readings of the three strain gages.

\section{Experimental Results}

\section{TENSILE FORCE PER UNIT WIDTH VERSUS STRAIN RESPONSE}

The failure modes of the tested specimens are determined as lateral or longitudinal splitting (Fig. 3). The failure location of the tested specimens was found to be at the ends, middle, or at another location. As expected, the most common failure mode was the lateral rupture of the coupons at the specimens' mid length.

The tensile forces per unit width versus the average strains of the tested specimens are shown in Fig. 4. Initially during the early stages of loading the CFRP coupons, stress-strain responses were perfectly linear due to the elastic nature of the material. However, during the later stages of loading, the tensile force per unit width versus strain response of some of the CFRP specimens deviated slightly from the perfectly linear relationship. Some slippage occurred at close to failure for a few specimens, as shown in Fig. 4. This behavior at the later stages has been previously reported by others $[5,20]$ and is the consequence of the gradual stiffening of the CFRP due to the straightening of the fibers. As a result, the secant modulus of the CFRP at the ultimate strain is slightly different from the elastic 
FIG. 3 Failure modes of FRP coupons.

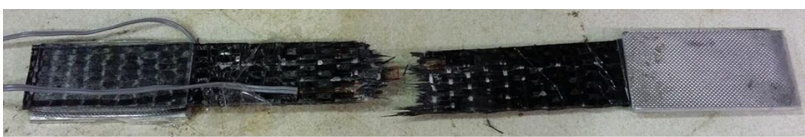

Specimen $\mathrm{C} 25 \_1$ with lateral failure type

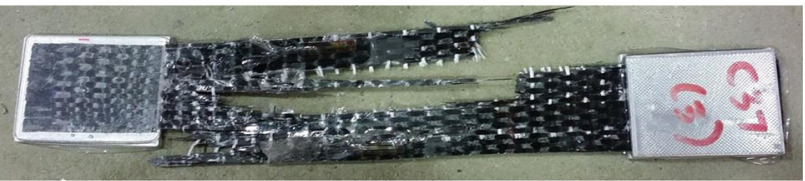

Specimen C37.5_3 with long splitting failure type

modulus computed according to ASTM D3039 [14]. In the interpretation of the test results, the gradual stiffening and the slippage at the later stages of testing are ignored. In other words, the stress-strain relationship was modified based on the assumption that the CFRP composite is perfectly linear in nature, and the rupture strain was determined based on the linear trend.

\section{TENSILE PROPERTIES}

A total of 20 specimens or five specimens per group were tested and presented. The results of the tensile testing are shown in Tables 2 and 3. The maximum tensile force per unit width $\left(F^{*}\right)$, ultimate strain $\left(\varepsilon_{f}\right)$, and the chord tensile stiffness per unit width $\left(K^{*}\right)$ of the Group C25 were, respectively, $2025 \mathrm{~N} / \mathrm{mm}, 1.70 \%$ and $114.6 \mathrm{kN} / \mathrm{mm}$. The corresponding values of the Group F25 were $2193 \mathrm{~N} / \mathrm{mm}, 1.78 \%$ and $116.8 \mathrm{kN} / \mathrm{mm}$, respectively. The tensile properties of Group F25 were found to be greater than that of Group C25. The maximum tensile force per unit width and the ultimate strain of Group F25 specimens were 8 and $5 \%$ higher than that of Group C25, respectively. Moreover, the maximum tensile force per unit width and the ultimate strain of Group F37.5 were both 5 \% higher than those of Group C37.5. However, the chord tensile stiffness per unit width of the two groups was similar.

\section{BENDING EFFECTS}

The $\%$ bending of the tested specimens was calculated following Eqs 2-4, which were used to evaluate the bending effects. ASTM D7565 [15] states that good testing practice is generally able to limit \% bending about the width plane and thickness plane as calculated by Eq 4 , to a range of $3 \%-5 \%$ at moderate strain levels $(>1000 \mu \varepsilon)$. Initially, specimens experienced \% bending exceeding these levels, which showed that either the alignment of the machine was unsatisfactory, specimen preparation was poor, or that the specimens were installed improperly in the grips, with ultimate strengths and strains below average for the respective group. Therefore, the results of these specimens were excluded. Following a few tests, additional care was taken to improve both the preparation process of the specimens and their alignment. No slippage or excessive bending occurred

FIG. 4 Tensile force per unit width versus average strain relationships for the specimens.

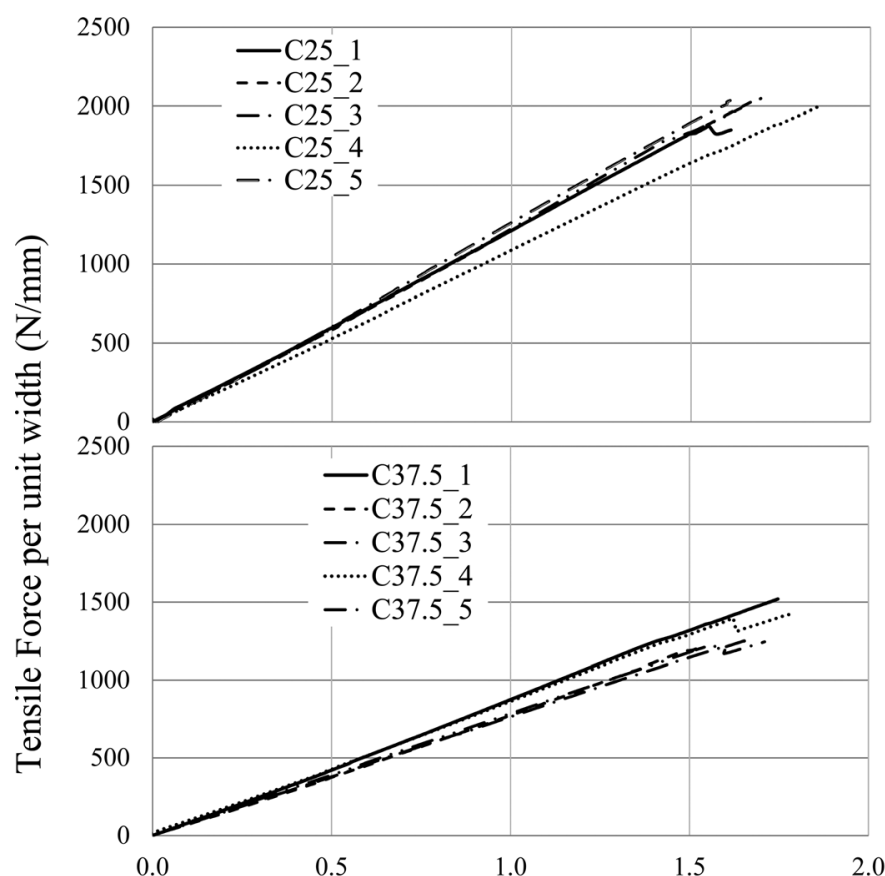

0.0
0.5
1.0

1.5

Average Strain (\%) 
TABLE 2 Tensile properties of CFRP coupon tests (width $25 \mathrm{~mm}$ ).

\begin{tabular}{lcccccc}
\hline Sample & $\begin{array}{c}F^{*} \\
(\mathrm{~N} / \mathrm{mm})\end{array}$ & $\begin{array}{c}\varepsilon_{a v e} \\
(\%)\end{array}$ & $\begin{array}{c}B_{y} \\
(\%)\end{array}$ & $\begin{array}{c}B_{z} \\
(\%)\end{array}$ & $\begin{array}{c}K^{*} \\
(\mathrm{kN} / \mathrm{mm})\end{array}$ & $\begin{array}{c}\text { Width } \\
(\mathrm{mm})\end{array}$ \\
\hline C25_1 & 1901 & 1.59 & OK & OK & 114.0 & 25.72 \\
C25_2 & 2048 & 1.69 & OK & OK & 115.1 & 24.73 \\
C25_3 & 1988 & 1.61 & OK & OK & 115.8 & 25.66 \\
C25_4 & 1994 & 1.85 & OK & X & 105.0 & 24.69 \\
C25_5 & 2192 & 1.76 & OK & OK & 123.4 & 24.86 \\
C25_average & 2025 & 1.70 & - & - & 114.64 & 25.13 \\
SD & 107.3 & 0.11 & - & - & 6.55 & 0.51 \\
CV ${ }^{b}$ (\%) & 5.30 & 6.28 & - & - & 5.71 & 2.04 \\
F25_1 & 2136 & 1.74 & OK & X & 120.4 & 23.82 \\
F25_2 & 2149 & 1.73 & OK & OK & 118.9 & 24.57 \\
F25_3 & 2275 & 1.83 & OK & X & 116.7 & 25.09 \\
F25_4 & 2179 & 1.73 & OK & OK & 114.1 & 23.63 \\
F25_5 & 2228 & 1.86 & OK & OK & 114.0 & 25.20 \\
F25_average & 2193 & 1.78 & - & - & 116.8 & 24.46 \\
SD & 57.80 & 0.06 & - & - & 2.85 & 0.71 \\
CV (\%) & 2.64 & 3.46 & - & - & 2.44 & 2.92 \\
\hline
\end{tabular}

${ }^{\mathrm{a}}$ The standard deviation.

${ }^{\mathrm{b}}$ The coefficient of variation.

Note: OK means the percent bending less than $5 \%$, X means the percent bending greater than $5 \% ; F^{*}=$ maximum tensile force per unit width; $B_{y}=$ percent bending about system $y$-axis (about the narrow plane); $B_{z}=$ percent bending about system $z$-axis (about the wide plane); $K^{*}=$ the chord tensile stiffness per unit width; $\varepsilon_{\text {ave }}$ is calculated based on Eq 5 .

TABLE 3 Tensile properties of CFRP coupon tests (width $37.5 \mathrm{~mm}$ ).

\begin{tabular}{lcccccc}
\hline Sample & $\begin{array}{c}F^{*} \\
(\mathrm{~N} / \mathrm{mm})\end{array}$ & $\begin{array}{c}\varepsilon_{f} \\
(\%)\end{array}$ & $\begin{array}{c}B_{y} \\
(\%)\end{array}$ & $\begin{array}{c}B_{z} \\
(\%)\end{array}$ & $\begin{array}{c}K^{*} \\
(\mathrm{kN} / \mathrm{mm})\end{array}$ & $\begin{array}{c}\text { Width } \\
(\mathrm{mm})\end{array}$ \\
\hline C37.5_1 & 1520 & 1.75 & $\mathrm{OK}^{\mathrm{c}}$ & $\mathrm{OK}$ & 83.4 & 36.92 \\
C37.5_2 & 1225 & 1.60 & $\mathrm{OK}$ & $\mathrm{OK}$ & 73.3 & 36.98 \\
C37.5_3 & 1252 & 1.58 & $\mathrm{OK}$ & $\mathrm{OK}$ & 76.6 & 39.21 \\
C37.5_4 & 1429 & 1.59 & $\mathrm{X}^{\mathrm{d}}$ & $\mathrm{OK}$ & 79.7 & 38.15 \\
C37.5_5 & 1244 & 1.65 & $\mathrm{OK}$ & $\mathrm{X}$ & 75.5 & 37.82 \\
C37_average & 1334 & 1.63 & - & - & 77.7 & 37.81 \\
SD & 132.54 & 0.07 & - & - & 3.94 & 0.94 \\
CV & 9.94 & 4.26 & - & - & 5.07 & 2.49 \\
F37.5_1 & 1359 & 1.63 & OK & OK & 79.6 & 38.40 \\
F37.5_2 & 1430 & 1.74 & OK & OK & 76.6 & 37.47 \\
F37.5_3 & 1332 & 1.61 & OK & OK & 78.9 & 37.22 \\
F37.5_4 & 1435 & 1.85 & OK & OK & 74.4 & 37.23 \\
F37.5_5 & 1472 & 1.75 & OK & OK & 78.2 & 36.18 \\
F37_average & 1406 & 1.72 & - & - & 77.6 & 37.30 \\
SD & 57.99 & 0.10 & - & - & 2.08 & 0.79 \\
CV & 4.13 & 5.63 & - & - & 2.69 & 2.13 \\
\hline
\end{tabular}

${ }^{\mathrm{a}}$ The standard deviation.

${ }^{\mathrm{b}}$ The coefficient of variation.

${ }^{\mathrm{c}}$ The percent bending less than $5 \%$.

${ }^{\mathrm{d}}$ The percent bending greater than $5 \%$.

Note: $F^{*}=$ maximum tensile force per unit widt $h$; $B_{y}=$ percent bending about system $y$-axis (about the narrow plane); $B_{z}=$ percent bending about system $z$-axis (about the wide plane); $K^{*}=$ the chord tensile stiffness per unit width; $\varepsilon_{\text {ave }}$ is calculated based on Eq 5 . for the presented specimens, although some specimens experienced $\%$ bending of over $5 \%$, as shown in Figs. 5 and 6.

Bending stresses inadvertently arise as a result of the misalignment between the specimen axes and the applied force during the application of tensile forces ASTM E1012-14 [21]. Ideally, the centerlines of the top and bottom grips of the machine should be precisely aligned with one another and with the centerline of the specimen. Additionally, the specimen should be symmetric about its centerline. However, differences from the ideal situation are due to poor specimen preparation and poor system alignment.

ASTM E1012 [21] states that testing machines as-received from manufacturers may have deviations between the top and bottom centerline grip positions ranging from 0.03 to $3.18 \mathrm{~mm}$ or more. In addition, applied forces subjected by the machine results in further misalignment due to the machine frame deflections. It has been reported that in the worst case, the deviations in this range has resulted in a difference between extreme surface bending strains and average strains of between 50 and $100 \%$ [21]. Therefore, conducting a tensile test with the \% bending between 3 and $5 \%$ is challenging.

The system alignment or bending behavior of the specimens was analyzed by plotting the $\%$ bending about the width $\left(B_{z}\right)$ and thickness plane $\left(B_{y}\right)$ versus the axial average strain obtained from the three strain gages, as shown in Figs. $\mathbf{5}$ and $\mathbf{6}$, respectively. ASTM D3039 [14] states that although the maximum advisable amount of system alignment is location- and material-dependent, a good testing practice is generally able to limit $\%$ bending to a range of $3 \%-5 \%$ at moderate strain levels greater than $1000 \mu \varepsilon$.

For simplicity, the $\%$ bending by the thickness plane and width plane will be referred to as $B_{y}$ and $B_{z}$, respectively. First, the analysis of the \% bending $\left(B_{z}\right)$ about the width plane versus the average strain is presented. It should be noted that for most of the specimens, $B_{y}$ and $B_{z}$ were very large during the early stages of loading. These large bending values may be due to the stabilization of the loading or other factors and were ignored in the analysis by plotting $B_{z}$ from average strains of $0.1 \%$ (see Fig. 5). As can be seen from Fig. 5, there was no common trend with the relationship of $B_{z}$ versus average strain. Most of the tested specimens had the \% bending about system $z$-axis lower than $5 \%$. However, the \% bending at the later stage when the tested specimen almost failed and thus fluctuated as compared to the earlier stages. It is assumed that a specimen that had the $\%$ bending greater than $5 \%$ may cause deviation from the average values, as experienced for the initially tested specimens. However, the experimental results presented in this study showed that the \% bending did not cause considerable deviation in the tensile properties of the CFRP coupon tests. For instance, Specimen F25_3 had $10 \%$ bending, which led to $4 \%$ difference in the maximum tensile force per unit width and $3 \%$ difference in the ultimate strain. 
FIG. 5 Percent bending about system z-axis.

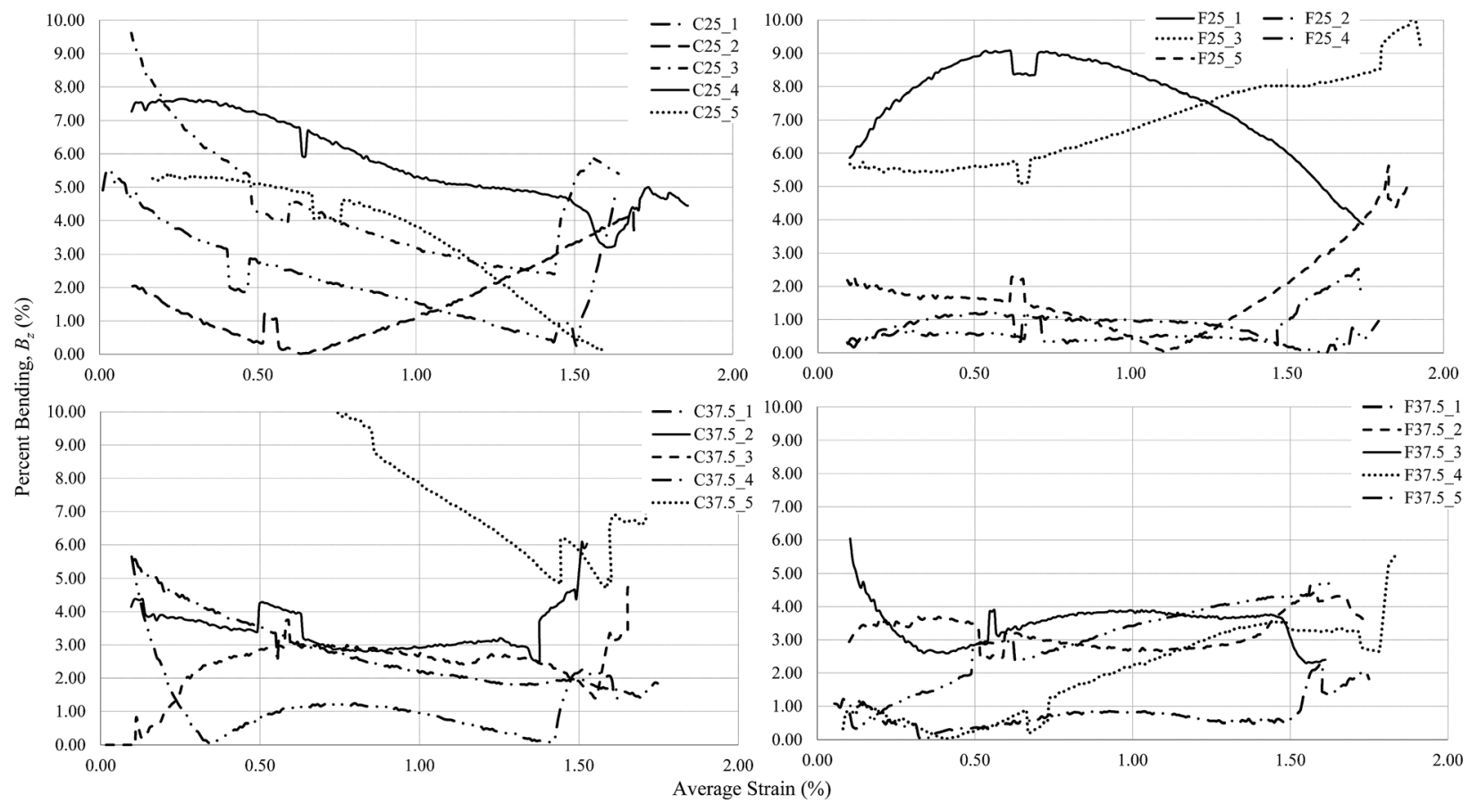

Based on the analysis of the \% bending about the thickness plane $\left(B_{y}\right), 90 \%$ of the specimens experienced bending $B_{y}$ of less than $3 \%$. For the remaining specimens, excluding Specimen C $37-5$, the $\%$ bending was between 3 and $5 \%$ for the majority of the loading, as shown in Fig. 6. Generally, the \% bending $B_{y}$ was stable from the axial strain of about $0.5 \%$, which is different to that of the \% bending $B_{z}$.

In summary, no apparent trend was noticed in the bending versus average strain relationships. It was seen that the level of bending in the specimens presented in this study did not

FIG. 6 Percent bending about system y-axis.

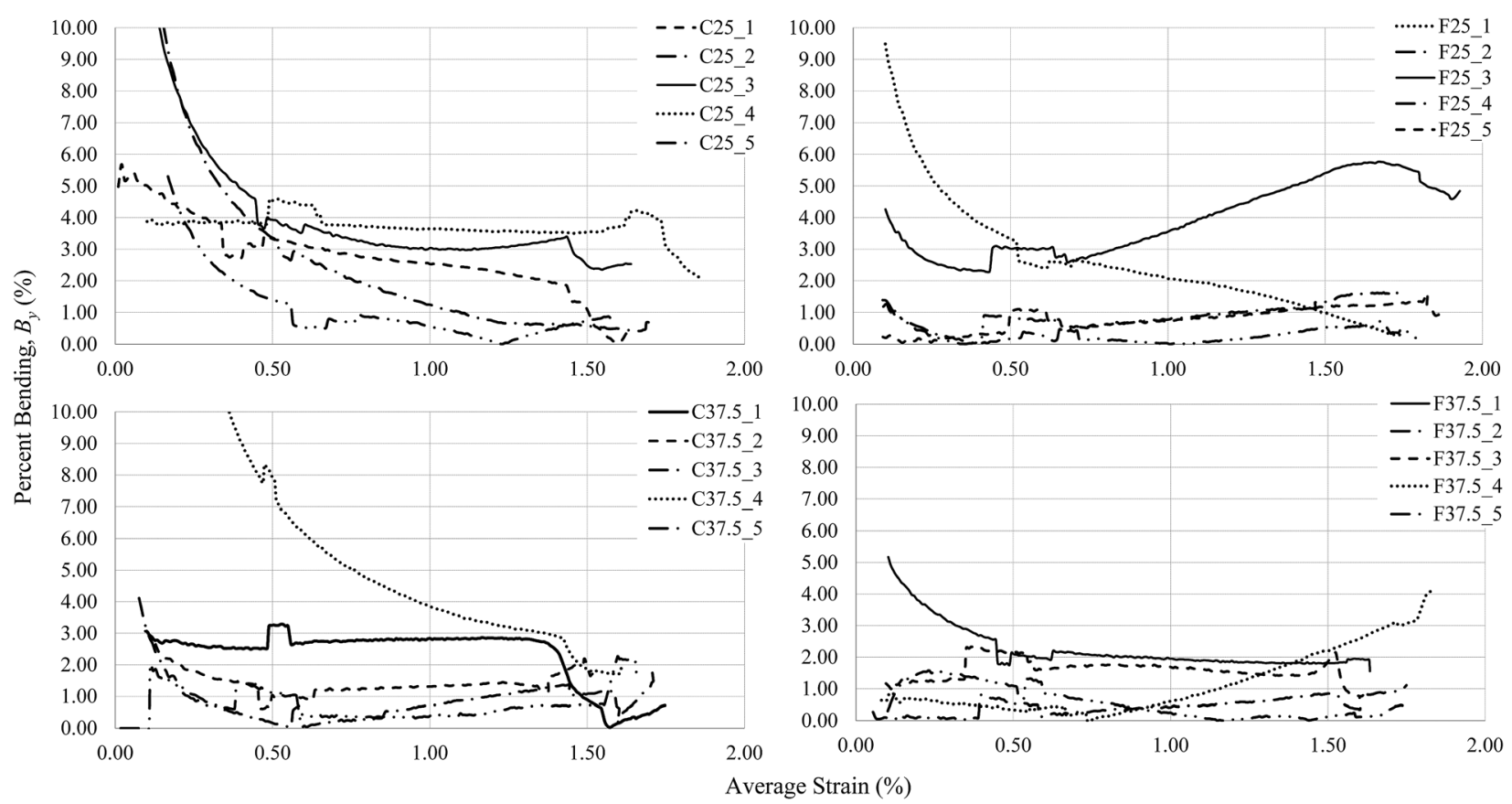


necessarily dictate the ultimate strength or strain of the specimens. Specimens with higher levels of bending did not necessarily have reduced ultimate strengths or strains compared to those specimens with lower bending values. In addition, bending about the width plane resulted in higher levels compared to bending about the thickness plane.

\section{Discussion}

\section{FABRICATION TECHNIQUE}

ASTM D7565 [15] recommends preparing FRP coupons made of dry fiber preform from an FRP laminate having a minimum dimension of 300 by $300 \mathrm{~mm}$. The standard does not include FRPs material with widths less than $300 \mathrm{~mm}$. It is noted that the standard focuses more on the thickness of the FRP sheets rather than their width. The width, in general, does not affect the tensile properties of FRP sheets, but it causes difficulties in specimen fabrication. Studies that used FRP sheets with a width less than $300 \mathrm{~mm}[16,22]$ struggled to conduct the FRP coupon tests in accordance with ASTM D7565 [15]. Therefore, ASTM D7565 [15] should consider taking this issue into account in the future revised version.

Experimental results from this study showed that FRP coupons prepared using the Folding Technique provides higher tensile properties than that of the Cutting Technique recommended by ASTM D7565 [15]. As mentioned above, the reduction of the tensile properties of FRP coupons made by the Cutting Technique was caused by the reduction in the number of fiber in identical coupons. This reduction resulted from the misalignment of the fibers combined with the cutting of the specimens. As shown in Fig. 7, even though special care was taken in the cutting process to minimize the exposure of the fibers, some fibers were damaged and exposed, which may lead to the reduction of the tensile properties and premature failure.

FIG. 7 Exposure of reinforcing fibers.

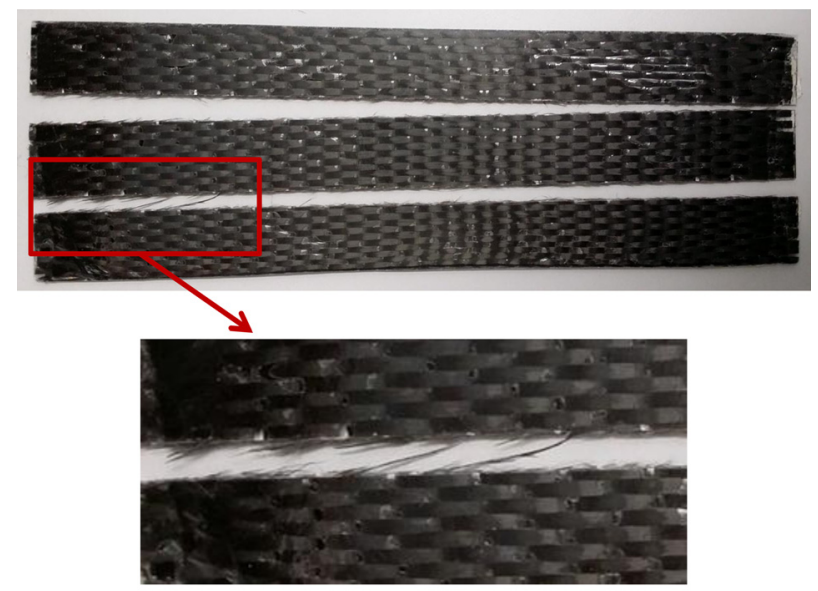

Exposure of reinforcing fibers
The experimental results also confirmed that the fabrication technique did not affect the \% bending as shown in Figs. 5 and 6. The $\%$ bending of the four groups seemed to be independent of the fabrication technique. However, the fabrication technique affected the standard deviation $(S D)$ and the coefficient of variation $(C V)$. Most notably, the experimental results from Tables 2 and $\mathbf{3}$ showed that the Folding Technique provided less $S D$ and $C V$ than that of the Cutting Technique. The $S D$ and $C V$ of the Folding Technique were approximately half of that obtained for the Cutting Technique. For example, the values of the $S D$ and $\mathrm{CV}$ in calculating the maximum tensile force per unit width of Group C25 were, respectively, $107.3 \mathrm{~N} / \mathrm{mm}$ and $5.30 \%$, while the corresponding numbers of Group F25 were $57.8 \mathrm{~N} / \mathrm{mm}$ and $2.64 \%$. It means that the Folding Technique delivers more reliable results in comparison with the Cutting Technique.

\section{THE WIDTH OF THE COUPONS}

ASTM D7565 [15] recommends that the variation in specimen width should be no greater than $\pm 1 \%$. However, the tested coupons implemented by the wet lay-up method can be affected by experience and workmanship. As a result, it is difficult to maintain the variation of the specimen width within $\pm 1 \%$. Experimental results from Tables $\mathbf{2}$ and $\mathbf{3}$ stated that the variation in specimen width of Groups C25, F25, C37.5, and F37.5 were $2.0 \%, 2.9 \%, 1.7 \%$, and $2.1 \%$, respectively.

In the specimen fabrication, a metal shear machine was used to cut a large laminated FRP into small FRP coupons that had widths of 25 or $37.5 \mathrm{~mm}$. It is assumed that one cut can yield the same number of fibers damaged. This cut yielded the same number of damaged fibers in one $25 \mathrm{~mm}$ coupon or 37.5 $\mathrm{mm}$ coupon. In order to investigate this parameter, the ratio between the number of the damaged fibers and the number of the total fibers is defined as the damage ratio. Meanwhile, the number of total fibers in the $37.5 \mathrm{~mm}$ coupon is greater than that of the $25 \mathrm{~mm}$ coupon. Therefore, the damage ratio of the $25 \mathrm{~mm}$ coupon is greater than that of the $37.5 \mathrm{~mm}$ coupon.

According to the Cutting Technique, this ratio indicates that wider coupons have smaller damage ratios as compared to smaller coupons. In such cases, the damage ratio is an indicator of the reduction in the tensile strength. For instance, the damage ratio of the $25 \mathrm{~mm}$ width coupons is greater than that of the $37.5 \mathrm{~mm}$ width coupons. Therefore, the difference in tensile strength between Groups C25 and F25 is larger than that between Group C37.5 and F37.5 (see Tables 2 and 3). For instance, the increase of the maximum tensile force per unit width of Group F25 compared to Group C25 was $8 \%$, while the corresponding number between Group F37.5 compared to Group C37.5 was only $5 \%$.

\section{BENDING EFFECTS}

The \% bending was determined for all the specimens tested. The ASTM D3039 [14] standard recommends testing one 
specimen to determine the system misalignment. However, other factors such as poor specimen preparation and improper placement of specimen in the grips could be a cause of bending. To check for specimen bending, the standard also mentions testing at least one specimen per like sample with back to back transducers (Clause 11.6.1). Therefore, considering factors other than system misalignment play a role in bending, all the specimens, rather than only one, should be tested to calculate the \% bending for the whole system and the specimen. The bending of the coupons is a function of both the testing machine and the coupon itself.

\section{Conclusions}

This study investigated the fabrication technique of FRP coupons and their tensile properties. The fabrication technique considerably affected the tensile properties of FRP coupons but did not result in considerable deviation in the \% bending. The findings presented in this study are summarized as follows:

1. FRP coupons prepared using the Folding Technique provided higher tensile properties as compared to coupons prepared using the Cutting Technique.

2. The $\%$ bending about the system $\mathrm{z}$ axis was greater than that about the $y$-axis. The tensile properties of the FRP coupons that were presented in this study were not sensitive to its \% bending.

3. The recommendation of a minimum 300 by $300 \mathrm{~mm}$ laminate FRP when preparing FRP coupons needs to be taken into account in order to suit FRP sheets that have widths less than $300 \mathrm{~mm}$.

4. Reducing the variability of the specimen widths to less than $1 \%$ is difficult to achieve.

Finally, the experimental results showed that the Folding Technique provides more consistent and reliable results as compared to the Cutting Technique. It is recommended that all the specimens are tested for bending effects rather than testing only one specimen as recommended by the standard. The reason for this is that factors other than system misalignment, such as poor specimen preparation and improper placement of the specimen, can play a role in specimen bending, producing variable test results.

\section{ACKNOWLEDGMENTS}

The first author would like to acknowledge the Vietnamese Government and the University of Wollongong for the support of his full $\mathrm{PhD}$ scholarship. The third author thanks the University of Wollongong for his PhD scholarship. The technical assistance from Mr. Cameron Neilson is appreciated.

\section{References}

[1] Wu, Y. F., Liu, T., and Oehlers, D. J., "Fundamental Principles That Govern Retrofitting of Reinforced
Concrete Columns by Steel and FRP Jacketing," $A d v$. Struct. Eng., Vol. 9, No. 4, 2006, pp. 507-533.

[2] Nanni, A. and Bradford, N. M., "FRP Jacketed Concrete Under Uniaxial Compression," Constr. Build. Mater., Vol. 9, No. 2, 1995, pp. 115-124.

[3] Pham, T. M. and Hadi, M. N. S., "Confinement Model for FRP Confined Normal- and High-Strength Concrete Circular Columns," Constr. Build. Mater., Vol. 69, 2014, pp. 83-90.

[4] Chen, J. F., Ai, J., and Stratford, T. J., "Effect of Geometric Discontinuities on Strains in FRP-Wrapped Columns," J. Compos. Constr., Vol. 14, No. 2, 2010, pp. 136-145.

[5] Lam, L. and Teng, J. G., "Ultimate Condition of Fiber Reinforced Polymer-Confined Concrete," J. Compos. Constr., Vol. 8, No. 6, 2004, pp. 539-548.

[6] Pham, T. M. and Hadi, M. N. S., "Strain Estimation of CFRP Confined Concrete Columns Using Energy Approach," J. Compos. Constr., Vol. 17, No. 6, 2013, 04013001.

[7] Pham, T. M. and Hadi, M. N. S., "Stress Prediction Model for FRP Confined Rectangular Concrete Columns With Rounded Corners," J. Compos. Constr., Vol. 18, No. 1, 2014, 04013019.

[8] Lam, L. and Teng, J. G., "Design-Oriented Stress-Strain Model for FRP-Confined Concrete," Constr. Build. Mater., Vol. 17, Nos. 6-7, 2003, pp. 471-489.

[9] Hawileh, R. A., Rasheed, H. A., Abdalla, J. A., and Al-Tamimi, A. K., "Behavior of Reinforced Concrete Beams Strengthened With Externally Bonded Hybrid Fiber Reinforced Polymer Systems," Mater. Des., Vol. 53, 2014, pp. 972-982.

[10] Dong, Q. and Gu, X., "Laboratory Test and Numerical Simulation of Bond Performance Between Basalt Fiber Reinforced Polymer Rebar and Concrete," J. Test. Eval., Vol. 40, No. 7, 2012, pp. 1-8.

[11] Gu, X., Dai, Y., and Jiang, J., "Test and Evaluation for Bonding Property Between GFRP and Concrete," J. Test. Eval., Vol. 44, No. 2, 2015, 20150165.

[12] Toufigh, V., Ouria, A., Desai, C. S., Javid, N., Toufigh, V., and Saadatmanesh, H., "Interface Behavior Between Carbon-Fiber Polymer and Sand," J. Test. Eval., Vol. 44, No. 1, 2015, 20140153.

[13] Wu, Y. F. and Jiang, J. F., "Effective Strain of FRP for Confined Circular Concrete Columns," Compos. Struct., Vol. 95, 2013, pp. 479-491.

[14] ASTM D3039/D3039M-14, Standard Test Method for Tensile Properties of Polymer Matrix Composite Materials, ASTM International, West Conshohocken, PA, 2014, www.astm.org

[15] ASTM D7565/D7565M-10, Standard Test Method for Determining Tensile Properties of Fiber Reinforced Polymer Matrix Composites Used for Strengthening of Civil Structures, ASTM International, West Conshohocken, PA, 2010, www.astm.org

[16] Hadi, M. N. S., Pham, T. M., and Lei, X., "New Method of Strengthening Reinforced Concrete Square Columns by Circularizing and Wrapping With Fiber-Reinforced Polymer or Steel Straps," J. Compos. Constr. Vol. 17, No. 2, 2013, pp. 229-238. 
[17] Pham, T. M. and Hao, H., "Impact Behavior of FRPStrengthened RC Beams Without Stirrups," J. Compos. Constr., Vol. 20, No. 4, 2016, 04016011.

[18] Pham, T. M., Hadi, M. N. S., and Tran, T. M., "Maximum Usable Strain of FRP-Confined Concrete," Constr. Build. Mater., Vol. 83, 2015, pp. 119-127.

[19] Pham, T. M., Hadi, M. N. S., and Youssef, J., "Optimized FRP Wrapping Schemes for Circular Concrete Columns," J. Compos. Constr., Vol. 19, No. 6, 2015, 04015015.

[20] fib (Fédération Internationale du Béton [International Federation for Structural Concrete]), "Externally Bonded FRP
Reinforcement for RC Structures," Bulletin 14, fib, 2001, p. 138.

[21] ASTM E1012-14, Standard Practice for Verification of Testing Frame and Specimen Alignment Under Tensile and Compressive Axial Force Application, ASTM International, West Conshohocken, PA, 2014, www.astm.org

[22] Pham, T. M., Doan, L. V., and Hadi, M. N. S., "Strengthening Square Reinforced Concrete Columns by Circularisation and FRP Confinement," Constr. Build. Mater., Vol. 49, 2013, pp. 490-499. 